\title{
Borocarbonitride Layers on Titanium Dioxide Nanoribbons for Efficient Photoelectrocatalytic Water Splitting
}

\author{
Nuria Jiménez-Arévalo ${ }^{1, *}$, Eduardo Flores ${ }^{2}\left(\mathbb{D}\right.$, Alessio Giampietri ${ }^{3}$, Marco Sbroscia ${ }^{3}$, Maria Grazia Betti ${ }^{3}{ }^{(0}$, \\ Carlo Mariani ${ }^{3}{ }^{(}$, José R. Ares ${ }^{1}$, Isabel J. Ferrer ${ }^{1,4}\left(\mathbb{D}\right.$ and Fabrice Leardini ${ }^{1,4}(\mathbb{D}$ \\ 1 Departamento de Física de Materiales, Campus de Cantoblanco, Universidad Autónoma de Madrid, \\ E-28049 Madrid, Spain; joser.ares@uam.es (J.R.A.); isabel.j.ferrer@uam.es (I.J.F.); fabrice.leardini@uam.es (F.L.) \\ 2 Centro de Nanociencias y Nanotecnología $(\mathrm{CNyN})$, Universidad Nacional Autónoma de México (UNAM), \\ Ensenada 22860, BC, Mexico; eduardoe.floresc@gmail.com \\ 3 Dipartimento di Fisica, Università di Roma 'La Sapienza', I-00185 Rome, Italy; \\ alessio.giampietri@uniroma1.it (A.G.); marco.sbroscia@uniroma1.it (M.S.); \\ maria.grazia.betti@roma1.infn.it (M.G.B.); carlo.mariani@uniroma1.it (C.M.) \\ 4 Instituto Nicolás Cabrera, Campus de Cantoblanco, Universidad Autónoma de Madrid, \\ E-28049 Madrid, Spain \\ * Correspondence: nuria.jimeneza@uam.es
}

check for updates

Citation: Jiménez-Arévalo, N.; Flores, E.; Giampietri, A.; Sbroscia, M.; Betti, M.G.; Mariani, C.; Ares, J.R.; J. Ferrer, I.; Leardini, F.

Borocarbonitride Layers on Titanium Dioxide Nanoribbons for Efficient Photoelectrocatalytic Water Splitting. Materials 2021, 14, 5490. https:// doi.org/10.3390/ma14195490

Academic Editor: Filippo Giannazzo

Received: 30 August 2021

Accepted: 16 September 2021

Published: 23 September 2021

Publisher's Note: MDPI stays neutral with regard to jurisdictional claims in published maps and institutional affiliations.

Copyright: (c) 2021 by the authors. Licensee MDPI, Basel, Switzerland. This article is an open access article distributed under the terms and conditions of the Creative Commons Attribution (CC BY) license (https:/ / creativecommons.org/licenses/by/ $4.0 /)$.
Abstract: Heterostructures formed by ultrathin borocarbonitride $(\mathrm{BCN})$ layers grown on $\mathrm{TiO}_{2}$ nanoribbons were investigated as photoanodes for photoelectrochemical water splitting. $\mathrm{TiO}_{2}$ nanoribbons were obtained by thermal oxidation of $\mathrm{TiS}_{3}$ samples. Then, $\mathrm{BCN}$ layers were successfully grown by plasma enhanced chemical vapour deposition. The structure and the chemical composition of the starting $\mathrm{TiS}_{3}$, the $\mathrm{TiO}_{2}$ nanoribbons and the $\mathrm{TiO}_{2}-\mathrm{BCN}$ heterostructures were investigated by Raman spectroscopy, $\mathrm{X}$-ray diffraction and X-ray photoelectron spectroscopy. Diffuse reflectance measurements showed a change in the gap from $0.94 \mathrm{eV}\left(\mathrm{TiS}_{3}\right)$ to $3.3 \mathrm{eV}\left(\mathrm{TiO}_{2}\right)$ after the thermal annealing of the starting material. Morphological characterizations, such as scanning electron microscopy and optical microscopy, show that the morphology of the samples was not affected by the change in the structure and composition. The obtained $\mathrm{TiO}_{2}-\mathrm{BCN}$ heterostructures were measured in a photoelectrochemical cell, showing an enhanced density of current under dark conditions and higher photocurrents when compared with $\mathrm{TiO}_{2}$. Finally, using electrochemical impedance spectroscopy, the flat band potential was determined to be equal in both $\mathrm{TiO}_{2}$ and $\mathrm{TiO}_{2}-\mathrm{BCN}$ samples, whereas the product of the dielectric constant and the density of donors was higher for $\mathrm{TiO}_{2}-\mathrm{BCN}$.

Keywords: borocarbonitride; $\mathrm{TiO}_{2}-\mathrm{BCN}$ heterostructures; water splitting; photoelectrocatalysis; $\mathrm{X}$-ray photoelectron spectroscopy; graphene analogues; hybrid structures

\section{Introduction}

The current energetic model based on fossil fuels is unsustainable from an environmental perspective, as it is one of the leading causes of global warming and climate change [1-3]. The focus is now placed on solar and wind energy, which have the problem of being intermittent, which points to the necessity of developing new ways of storing energy.

Among all the energy storage methods, energy storage using molecular bonding stands out, such as the one in the hydrogen molecule. Hydrogen has been reported to be a suitable energy vector and a clean energy fuel if its production comes from renewable sources $[2,4]$.

In 1972, Honda and Fujishima reported a way to obtain hydrogen by carrying out a photoassisted water splitting reaction using $\mathrm{TiO}_{2}$ as the photoanode [5]. Since then, this effect has been considered one of the cleanest methods to obtain green hydrogen and a promising strategy to overcome the environmental and energy crises [6,7]. The watersplitting reaction consists of two partial reactions, the oxygen evolution reaction (OER) and 
the hydrogen evolution reaction (HER). The OER is the rate-determining step as it involves the transfer of four electrons [8], and this is the reaction we will tackle in this paper.

The low cost, stability and non-toxicity of $\mathrm{TiO}_{2}$, as well as its adequacy to carry out the water splitting reaction, has drawn the attention of many groups who have reported the good properties of this material by synthesizing it in different structures and nanostructures $[9,10]$.

To increase the charge transfer between the electrode and the electrolyte, metals nanoparticles, such as $\mathrm{Pt}$ and $\mathrm{Ni}$, are commonly used as active electrocatalytic sites for water splitting [11]. The main focus is now placed on developing new metal-free compounds to be used as catalysts for the oxygen and hydrogen evolution reactions.

Graphene analogues and other 2D materials have demonstrated to be highly interesting metal-free compounds with a wide range of applications in electrocatalysis [12]. These layers have the advantage of being distributed along all the electrode surface, increasing the reaction area in comparison to the metal nanoparticles. Among these 2D materials borocarbonitride compounds (BCNs hereafter) stand out, which are low cost and highly stable materials formed by $\mathrm{h}-\mathrm{BN}$ and graphite domains. $\mathrm{BCNs}$ have been reported to be efficient electrocatalysts for the HER $[13,14]$ and, most interestingly, have recently been proved to be an efficient electrocatalysts for the OER, improving the properties of $\mathrm{TiO}_{x}$ substrates for this reaction [15].

In this article we have first confirmed the utility and versatility of plasma enhanced chemical vapor deposition to grow $\mathrm{BCN}$ on samples with different morphologies. This technique has been previously used to grow $\mathrm{BCN}$ on $\mathrm{TiO}_{\mathrm{x}}, \mathrm{Cu}$, and other flat substrates $[15,16]$. In this work, $\mathrm{BCN}$ was grown, for the first time, on nanostructured $\mathrm{TiO}_{2}$ samples. In particular, $\mathrm{BCN}$ was grown on $\mathrm{TiO}_{2}$ nanoribbons, obtained by the thermal annealing of $\mathrm{TiS}_{3}$ [17]. A deep characterization of $\mathrm{TiO}_{2}$ nanoribbons, with and without $\mathrm{BCN}$, as well as the starting material, $\mathrm{TiS}_{3}$, was made with scanning electron microscopy (SEM), X-ray diffraction (XRD), Raman spectroscopy and diffuse reflectance measurements. X-ray photoelectron spectroscopy (XPS) characterization of bare and $\mathrm{BCN}$-covered $\mathrm{TiO}_{2}$ nanoribbons was performed.

Finally, we demonstrated the good properties of the $\mathrm{BCN}$ as an electrocatalyst of the OER by improving the charge transfer between the $\mathrm{TiO}_{2}$ nanoribbons electrode and the $\mathrm{KOH}$ aqueous electrolyte, under dark and light conditions.

\section{Materials and Methods}

\subsection{Synthesis}

The starting $\mathrm{TiS}_{3}$ material has been obtained by the sulfuration of Ti disks $(15 \mathrm{~mm}$ diameter, Good Fellow 99.5\%) in sealed Pyrex ampoules for $20 \mathrm{~h}$ at $550{ }^{\circ} \mathrm{C}$, using sulfur powder as sulfur source $[18,19]$.

$\mathrm{TiS}_{3}$ nanoribbons were squashed in one direction and oxidized on a hot plate at $300{ }^{\circ} \mathrm{C}$ in air (the decomposition temperature of $\mathrm{TiS}_{3}$ [17]) for 20-30 s, which allowed us to obtain the desired $\mathrm{TiO}_{2}$ nanoribbons. Figure $\mathrm{S} 1$ shows the change in the color of the samples, from black to white, at a glance.

$\mathrm{BCN}$ was grown on $\mathrm{TiO}_{2}$ using $\mathrm{PE}-\mathrm{CVD}$ to get the $\mathrm{TiO}_{2}-\mathrm{BCN}$ heterostructures. The $\mathrm{TiO}_{2}$ sample and a single-source molecular precursor (methylamine-borane, $\mathrm{BH}_{3} \mathrm{NH}_{2} \mathrm{CH}_{3}$ ) were placed inside a Pyrex ampoule immersed in liquid nitrogen and then sealed under vacuum at a pressure around $10^{-5}$ mbar. When the sealed ampoule reaches room temperature, the molecular precursor is in equilibrium with its vapor pressure in the $10^{-2} \mathrm{mbar}$ range. Then a plasma was activated inside the ampoule using the radiation of a conventional microwave oven. More details about this technique can be found elsewhere $[15,16]$.

\subsection{Characterization}

The starting material, $\mathrm{TiS}_{3}$, as well as $\mathrm{TiO}_{2}$ and $\mathrm{TiO}_{2}-\mathrm{BCN}$ heterostructures, were characterized by using different techniques. 
The morphology of the samples was investigated by scanning electron microscopy (SEM) using a Hitachi S3000 instrument. Additionally, they were characterized using Raman spectroscopy with a WITec ALPHA 300AR instrument using a confocal microscope with lenses of $20 \times$ and $100 \times$. The used laser had a power of $0.2 \mathrm{~mW}$ and an excitation wavelength of $532.3 \mathrm{~nm}$.

The structural properties were measured using a Panalytical X'Pert Pro X-ray diffractometer at glancing angle configuration (incident angle of $1.7^{\circ}, \mathrm{CuK} \alpha$ radiation).

The optical reflectance spectra were recorded in a UV/VIS/NIR Perkin-Elmer LAMBDA 950 spectrophotometer equipped with an integrating sphere to collect the reflecting flux, using a spot size of $21 \mathrm{~mm}^{2}$ in the $300-2000 \mathrm{~nm}$ spectral range.

The composition on the surface of $\mathrm{TiO}_{2}$ and $\mathrm{TiO}_{2}-\mathrm{BCN}$ samples was investigated by $\mathrm{X}$-ray photoelectron spectroscopy (XPS). These measurements have been carried out in an ultrahigh-vacuum (UHV) chamber, with a base pressure in the low $10^{-10} \mathrm{mbar}$ range. Photoelectrons excited by an $\mathrm{Al} \mathrm{K} \alpha$ photon source $(h v=1486.7 \mathrm{eV})$, were measured by a hemispherical electron analyzer (VG Microtech Clam-2) in a pass energy mode set at $50 \mathrm{eV}$ for Ti and $\mathrm{C}$, and $100 \mathrm{eV}$ for $\mathrm{B}$ and N. Further details about the procedure are available in $[15,16,20,21]$. The binding energy (BE) was calibrated by acquiring the $A u 4 f_{7 / 2}(84.0 \mathrm{eV}$ of $\mathrm{BE}$ ) core-level after each measurement. The measurements were done after annealing the samples at $320^{\circ} \mathrm{C}$ for $1 \mathrm{~h}$, at $110^{\circ} \mathrm{C}$ for $15 \mathrm{~h}$ and $320^{\circ} \mathrm{C}$ for another hour in UHV.

Electrochemical measurements were done in a three-electrode cell. Our material, which had an apparent area of $1.3 \mathrm{~cm}^{2}$, was placed as the working electrode (WE), a platinum sheet $\left(9 \mathrm{~cm}^{2}\right)$ as the counter electrode (CE), and, as the reference electrode (RE), an $\mathrm{Ag} / \mathrm{AgCl}$ electrode filled with $1 \mathrm{M} \mathrm{KNO}_{3}$ (XR440 from Radiometer Analytical) was used. Its electrode potential was $484 \mathrm{mV}$ vs. a normal hydrogen electrode (NHE). These three electrodes were immersed in $0.1 \mathrm{M}(\mathrm{pH}=13.0)$ and $1.0 \mathrm{M}(\mathrm{pH}=13.7) \mathrm{KOH}$ aqueous electrolyte. The potentials are converted to the reversible hydrogen electrode (RHE) using Equations (1) and (2):

$$
\begin{gathered}
E_{N H E}=E_{A g / A g C l}+E_{A g / A g C l}^{0} \\
E_{R H E}=E_{N H E}+0.059 \cdot p H
\end{gathered}
$$

where $E_{N H E}$ is the electrode potential in the NHE scale, $E_{\mathrm{Ag} / \mathrm{AgCl}}$ is the experimental electrode potential measured vs. $\mathrm{Ag} / \mathrm{AgCl}$ reference electrode, $E_{\mathrm{Ag} / \mathrm{AgCl}}^{0}$ is the electrode potential vs. the NHE, $E_{R H E}$ is the electrode potential in the RHE scale, and $\mathrm{pH}$ is the $\mathrm{pH}$ of the solution used.

The electrochemical and photoelectrochemical (PEC) measurements were done using a potentiostat-galvanostat PGTAT302N (Autolab) provided with an integrated impedance module, FRAII. The WE was illuminated with a Xe lamp (Jobin Yvon) of $75 \mathrm{~W}$ in the visible-UV range. The maximum light intensity reaching the sample was $140 \mathrm{~mW}$. During electrochemical measurements, argon was bubbled at a constant flow of $20.0 \mathrm{sccm}$. To characterize the electrodes under both dark and illumination conditions, linear sweep voltammetry (LSV), cyclic voltammetry (CV) and current density measurements at a fixed potential were employed. In addition, electrochemical impedance spectroscopy (EIS) was used to characterize the interface electrolyte-semiconductor, by using a sinusoidal AC voltage signal with an amplitude of $10 \mathrm{mV}$ and a variable frequency between 100-1000 Hz.

More details about the photoelectrochemical experimental system can be found in the Supplementary Materials (Figure S2).

\section{Results and Discussion}

\subsection{Morphological and Structural Characterization}

The oxidation of the $\mathrm{TiS}_{3}$ nanoribbons was performed to change the atomic structure and the composition of the material, without changing the morphology of the sample, in order to obtain $\mathrm{TiO}_{2}$ nanoribbons. Figure 1a reports the morphology of $\mathrm{TiS}_{3}$ before and after the oxidation. It is clear from the SEM measurements, that there was no significant change in the morphology, apart from a slight increase of the roughness on the $\mathrm{TiO}_{2}$ 
surface compared to $\mathrm{TiS}_{3}$. We also acquired optical microscopy images to have a deeper understanding of the change on the surface of these nanoribbons (Figure 1b), which allowed us to determine that the material became more transparent to the optical microscope, in good agreement with the results reported by Ghasemi et al. [17] and with our optical characterizations shown below (see Figure 4).

(a)
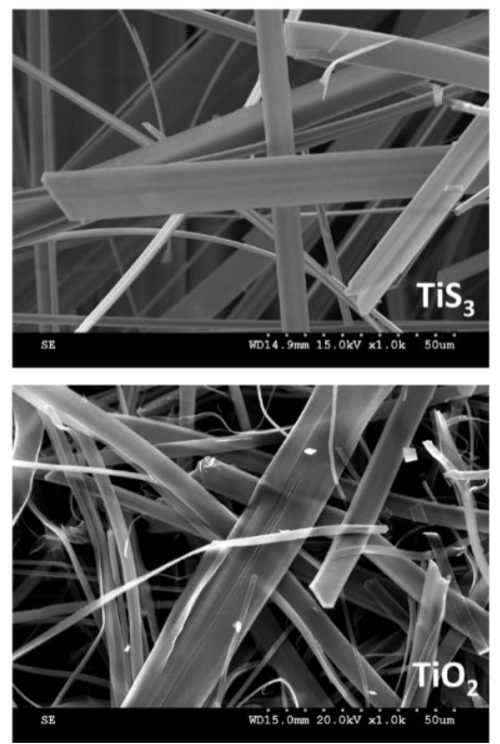

(b)
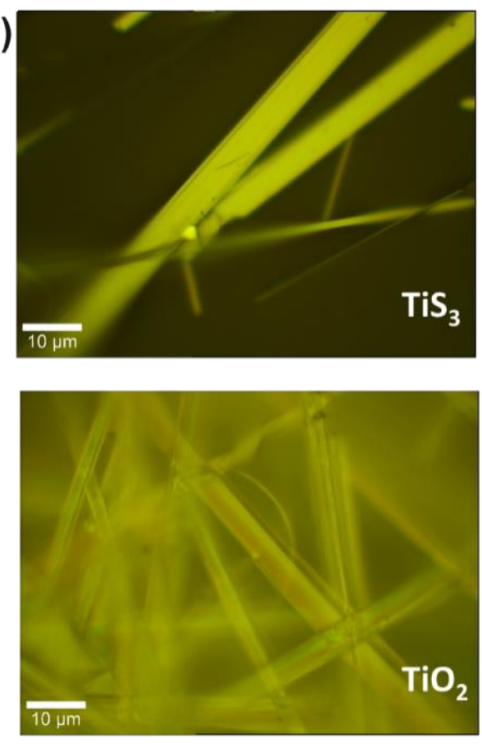

Figure 1. (a) Scanning electron micrographs of $\mathrm{TiS}_{3}$ (top) and $\mathrm{TiO}_{2}$ (bottom). (b) Optical microscopy image of $\mathrm{TiS}_{3}$ (top) and $\mathrm{TiO}_{2}$ (bottom).

Structural changes were also monitored via XRD after the oxidation and after growing the $\mathrm{BCN}$ on top of this oxidized material (Figure 2). There were clear changes in the structure due to the thermal annealing, as there was a transition from monoclinic $\mathrm{TiS}_{3}$ to tetragonal $\mathrm{TiO}_{2}$-anatase with some peaks of tetragonal $\mathrm{TiO}_{2}$-rutile.

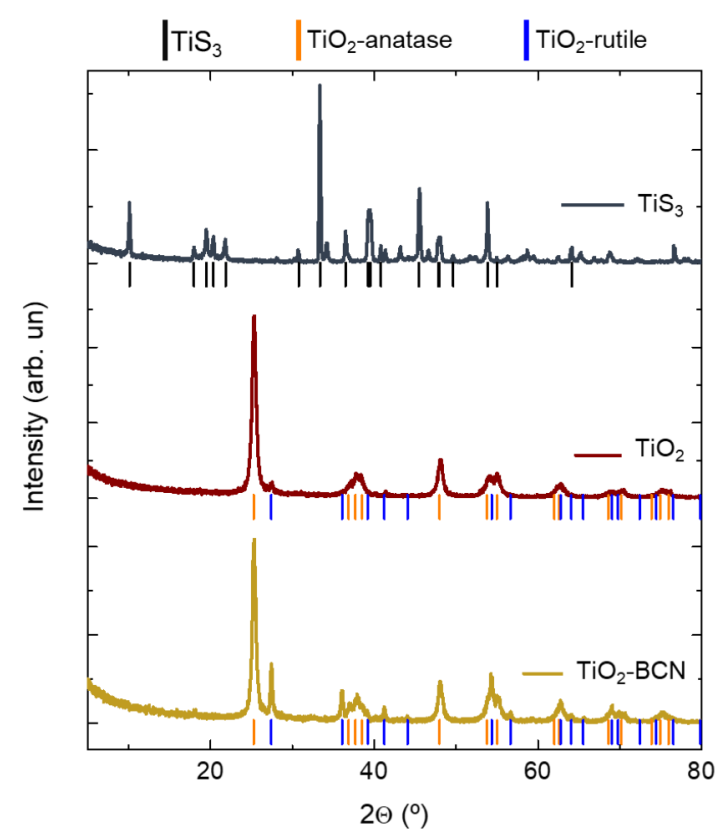

Figure 2. X-ray diffraction patterns for $\mathrm{TiS}_{3}, \mathrm{TiO}_{2}$ and $\mathrm{TiO}_{2}-\mathrm{BCN}$ samples. $\mathrm{TiS}_{3}$ peaks correspond to JDPDF 00-015-0783, $\mathrm{TiO}_{2}$-anatase peaks correspond to JDPDF 01-071-1167, and $\mathrm{TiO}_{2}$-rutile peaks correspond to JDPDF 01-073-2224. 
After the BCN synthesis, the intensity of the rutile peaks increased. This was ascribed to the high temperature that the sample achieved during exposure to the plasma, which modified the structure of the bulk material by crystallizing the sample from anatase $\mathrm{TiO}_{2}$ to rutile $\mathrm{TiO}_{2}$.

Raman spectra of $\mathrm{TiS}_{3}$ and $\mathrm{TiO}_{2}$ nanoribbons, reported in Figure 3, show that there is a complete change in their structure from TiS $3\left(175 \mathrm{~cm}^{-1}, 303 \mathrm{~cm}^{-1}, 373 \mathrm{~cm}^{-1}, 562 \mathrm{~cm}^{-1}\right)$ [22] to $\mathrm{TiO}_{2}$-anatase $\left(145 \mathrm{~cm}^{-1}, 396 \mathrm{~cm}^{-1}, 518 \mathrm{~cm}^{-1}, 643 \mathrm{~cm}^{-1}\right)[10,23,24]$. In the case of $\mathrm{TiO}_{2^{-}}$ $\mathrm{BCN}$, there was no change in the Raman spectra of the nanoribbons, thus they maintained their anatase composition. The growth of the $\mathrm{BCN}$ in this sample was confirmed by the presence of $\mathrm{D}\left(1375 \mathrm{~cm}^{-1}\right)$ and $\mathrm{G}\left(1590 \mathrm{~cm}^{-1}\right)$ Raman bands, ascribed to the BCN layers graphene-like sp2 structure [15,16].

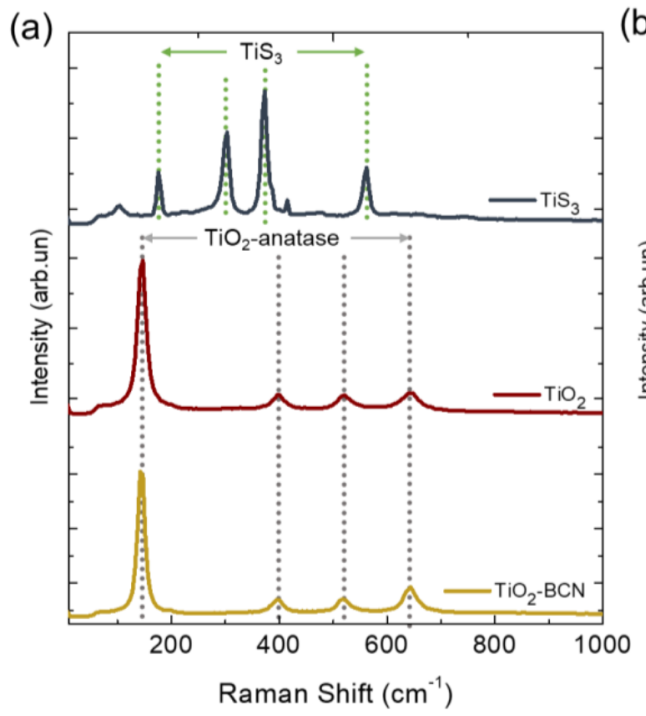

(b) $\times 40$

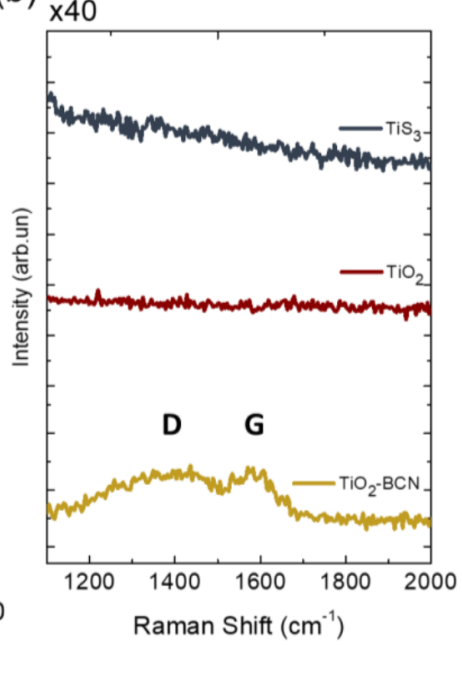

Figure 3. Raman spectra for $\mathrm{TiS}_{3}, \mathrm{TiO}_{2}$ and $\mathrm{TiO}_{2}-\mathrm{BCN}$ samples in the (a) $100-1000 \mathrm{~cm}^{-1}$ Raman shift range and (b) $1100-2000 \mathrm{~cm}^{-1}$ Raman shift range with a $\times 40$ zoom in the intensity.

It must be mentioned that in the $\mathrm{TiO}_{2}-\mathrm{BCN}$ sample, some $\mathrm{TiO}_{2}$ rutile nanoribbons $[25,26]$ were also found in the Raman spectra (Figure S3). This result is in good agreement with the increase in the rutile peaks in the XRD diffractogram for this sample. The nanoribbons were found at the borders of the samples and did not contribute to the electrochemistry as they were not exposed to the electrolyte due to the shape of the electrode holder.

\subsection{Optical Characterization}

Diffuse reflectance measurements were done using an integrating sphere to characterize the change in the energy bandgap. The reflectance $(R)$ data were converted into a Kubelka-Munk function, $F(R)$ [27] (Equation (3)), which was proportional to the optical density in the optical absorption measurements.

$$
F(R)=\frac{(1-R)^{2}}{2 R}
$$

Results as a function of the incident light energy can be seen in Figure 4a. At first glance, the presence of $1.23 \mathrm{eV}, 1.73 \mathrm{eV}$ and $2.1 \mathrm{eV}$ absorption bands, characteristic of the $\mathrm{TiS}_{3}$ samples [19] can be observed, but they disappear after the oxidation process due to the transformation of $\mathrm{TiS}_{3}$ into $\mathrm{TiO}_{2}$. 
(a)

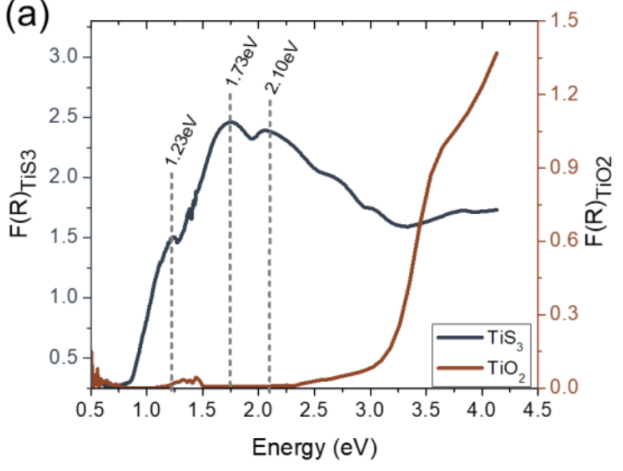

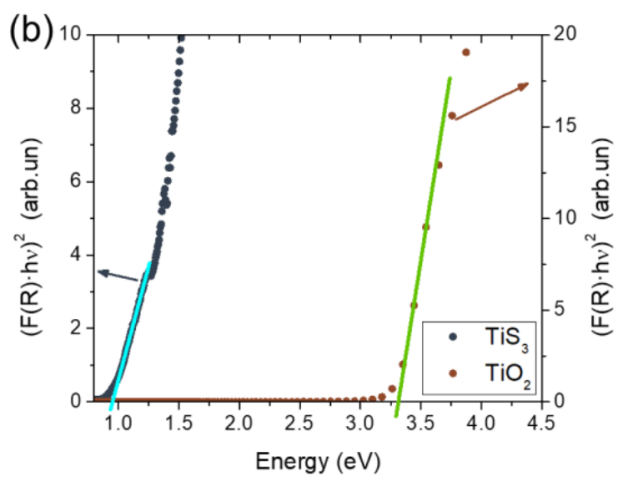

Figure 4. (a) Kubelka-Munk function obtained from diffuse reflectance measurements of $\mathrm{TiS}_{3}$ (left axis) and $\mathrm{TiO}_{2}$ (right axis). (b) Tauc plots of Kubelka-Munk function with the corresponding linear fit for $\mathrm{TiS}_{3}$ (left axis) and $\mathrm{TiO}_{2}$ (right axis).

To obtain the band gap energy of $\mathrm{TiS}_{3}$ and $\mathrm{TiO}_{2}$ samples, Tauc fitting equation for direct band gaps $\left((F(R) \cdot h v)^{2}\right)$ has been applied to the $\mathrm{F}(\mathrm{R})$ function (Figure $4 \mathrm{~b}$ ). A clear change can be observed from $0.94 \pm 0.04 \mathrm{eV}$ in $\mathrm{TiS}_{3}$, to $3.3 \pm 0.4 \mathrm{eV}$ in $\mathrm{TiO}_{2}$. These results are in good agreement with the values previously obtained for $\mathrm{TiS}_{3}$ [19] and $\mathrm{TiO}_{2}$ [28].

\subsection{Surface Chemical Composition and Element Distribution}

For further characterization of the chemical bonding state in the surface of $\mathrm{TiO}_{2}$ and $\mathrm{TiO}_{2}-\mathrm{BCN}$ samples, XPS measurements were carried out. The Ti2p level for the $\mathrm{TiO}_{2}$ sample is shown in Figure 5a, and the B1s, C1s and Ti2p core levels for $\mathrm{TiO}_{2}-\mathrm{BCN}$ can be seen in Figure $5 \mathrm{~b}-\mathrm{d}$. A fitting analysis using Voigt line shapes (combination of Gaussian and Lorentzian curves) was performed to take into account the overall experimental uncertainty and the intrinsic linewidth, respectively. A Shirley background was introduced as a fitting parameter for all the analyzed peaks. All the fitting parameters for the graphs in Figure 5 are reported in Table S1.

From this result, it is evident that the Ti2p levels show the presence of $\mathrm{Ti}^{4+}$ in both samples, which can be attributed to the formation of $\mathrm{TiO}_{2}$ [29]. However, in the case of $\mathrm{TiO}_{2}-\mathrm{BCN}$, a small additional peak at $457.55 \mathrm{eV}$ of $\mathrm{BE}$ appears, which is ascribed to the presence of $\mathrm{Ti}^{3+}$ bonds [30,31], probably due to small areas with defects close to the edge of the sample. Nevertheless, this component represents the $0.5 \%$ of the relative intensity, meaning that the plasma did not significantly affect the surface of the substrate for the growth times used.

In the $\mathrm{TiO}_{2}-\mathrm{BCN}$ sample, $\mathrm{XPS}$ measurements revealed that the $\mathrm{BCN}$ layer was composed of $C$ and h-BN domains with high mutual doping levels of $B$ and $N$ in $C$, and of $C$ in $\mathrm{BN}$, respectively. The B1s and C1s peaks appear with a large width and are composed of more than one peak, indicating the presence of different components associated with the mutual bonding among the elements.

The B1s core level in $\mathrm{TiO}_{2}-\mathrm{BCN}$ shows three peaks due to the $\mathrm{B}-\mathrm{C}(190.51 \mathrm{eV}), \mathrm{B}-\mathrm{N}$ $(191.41 \mathrm{eV})[15,16,21,32-34]$ and $\mathrm{B}-\mathrm{O}(192.96 \mathrm{eV})$ bonds $[15,16,20,21,35]$. The C1s core level exhibit four main components due to the $\mathrm{C}-\mathrm{C}$ bonding at $284.6 \mathrm{eV}$, signature of the sp2bonded carbon, $\mathrm{C}-\mathrm{N}$ bonds $(285.48 \mathrm{eV}), \mathrm{C}-\mathrm{B}$ bonds $(282.65 \mathrm{eV})$, and multiple components due to different bonds of $\mathrm{C}$ to $\mathrm{O}[15,16,21,32-34]$, which are unresolved and appear as a single broad band at $286.43 \mathrm{eV}$. We were not able to decompose the N1s peak in different Voigt functions, as we did with C1s and B1s peaks, since the signal of N1s is overlapped with a small signal of the Ta4 $\mathrm{p}_{3 / 2}$ peak, ascribed to the tantalum clips used to fix the sample to the sample holder. The spectrum in an energy range close to the N1s peak (385-413 eV) is shown in Figure S4. 

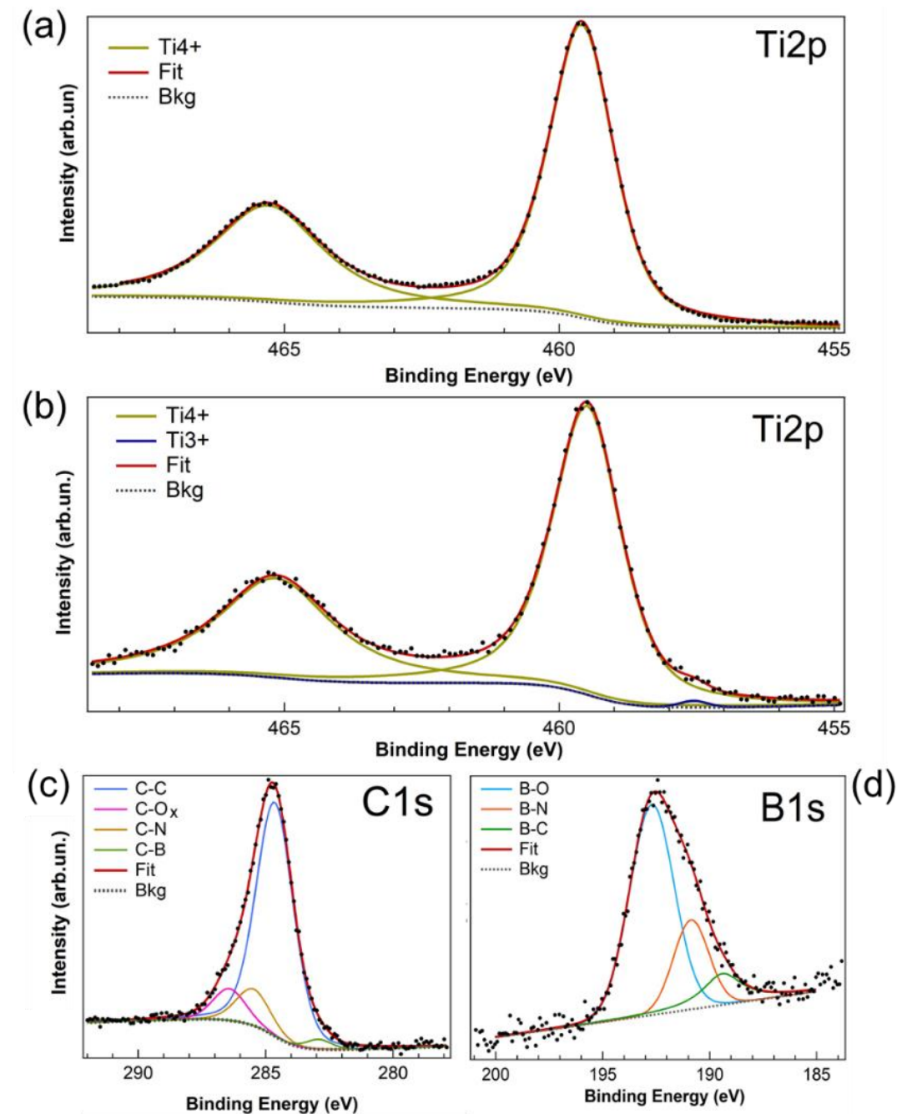

Figure 5. Ti2p XPS spectra for (a) $\mathrm{TiO}_{2}$ sample and (b) $\mathrm{TiO}_{2}-\mathrm{BCN}$ sample. $\mathrm{C} 1 \mathrm{~s}$ (c) and $\mathrm{B} 1 \mathrm{~s}$ (d) spectra for $\mathrm{TiO}_{2}-\mathrm{BCN}$ sample. Experimental data (dots), Shirley background is represented by a grey dotted line, the fitting curve for each measurement is in red, and single fitting components, as described in the legend.

Thus, the $\mathrm{B}$ and $\mathrm{C}$ 1s core levels present the typical features associated with the mutual chemical bonds in sp2-hybridized compounds. This is a clear signature of the formation of a ternary BCN planar layer $[15,16]$. The amount of BCN in the sample was estimated by XPS quantification, taking into account the cross-section, obtaining a ratio between $\mathrm{Ti}$ and $\mathrm{B}$ of 7:1, which suggests that the layer of $\mathrm{BCN}$ was ultrathin.

\subsection{Photoelectrocatalytic Activity for the OER}

The effect of $\mathrm{BCN}$ on the electrocatalytic activity of $\mathrm{TiO}_{2}$ was investigated at first via linear sweep voltammetry (LSV) measurements under intermittent illumination conditions comparing the results from $\mathrm{TiO}_{2}-\mathrm{BCN}$ heterostructure and these from bare $\mathrm{TiO}_{2}$ one (Figure 6a). Regarding the dark condition, bare $\mathrm{TiO}_{2}$ presented low currents and poor catalytic activity for the OER compared to those of the $\mathrm{TiO}_{2}-\mathrm{BCN}$ sample, which points out the electrocatalytic effect of $\mathrm{BCN}$. In fact, at the maximum applied potential $(1.9 \mathrm{~V}$ vs. RHE), the dark current was 12 -fold higher than that of the bare $\mathrm{TiO}_{2}$. Photocurrents were measured at different applied stationary potentials (Figure 6b), and, as can be seen, it increases from around $1 \mu \mathrm{A}$ (bare $\mathrm{TiO}_{2}$ ) to around $40 \mu \mathrm{A}\left(\mathrm{TiO}_{2}-\mathrm{BCN}\right)$ at $1.23 \mathrm{~V}$ vs. RHE. The photocurrents were stable (Figure S5) and have a positive value, in good agreement with the nature of $\mathrm{TiO}_{2}$ as an n-type semiconductor [36]. It can be concluded that the $\mathrm{BCN}$ layer does not only improves the electrocatalytic properties of the $\mathrm{TiO}_{2}$ at dark conditions, but also under illumination by increasing the photocurrents. The LSV curves, as well as $\mathrm{CV}$ curves, were measured for different scan rates, which made it possible to determine that the current that appears in the $\mathrm{TiO}_{2}-\mathrm{BCN}$ sample before the OER in the LSV curve is due to the scan rate and not to another reaction (Figure S6). 

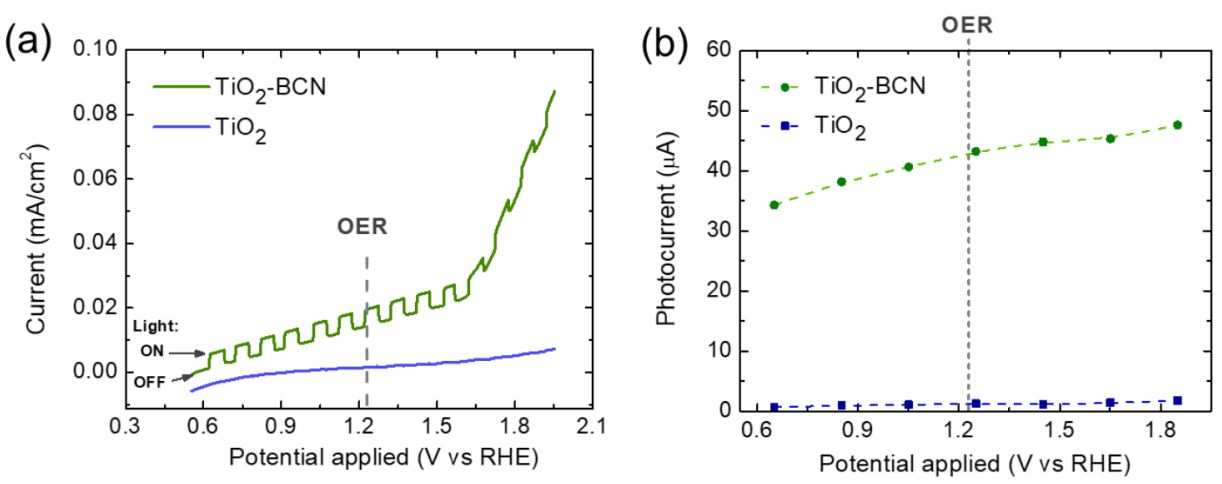

Figure 6. (a) Linear sweep voltammetry curves for bare $\mathrm{TiO}_{2}$ and $\mathrm{TiO}_{2}-\mathrm{BCN}$ under intermittent illumination conditions. (b) Photocurrents obtained for different constant applied potentials.

The stability has been monitored by doing series of 50 cycles at $0.05 \mathrm{~V} / \mathrm{s}$, proving the high stability of our material, as can be seen in Figure S7. Raman measurements were also made before and after the photoelectrochemical measurements to prove that there was no degradation of the sample and that the BCN layer was still there (Figure S8).

In order to characterize the interface between the electrodes $\left(\mathrm{TiO}_{2}\right.$ and $\left.\mathrm{TiO}_{2}-\mathrm{BCN}\right)$ and the electrolyte $(\mathrm{KOH})$, EIS measurements were done. By measuring the impedance at different frequencies, the capacitance in the spatial charge region $\left(C_{S C}\right)$ could be acquired, and with the Mott-Schottky equation (Equation (4)), the value of the flat band potential $\left(V_{f b}\right)$ could be obtained.

$$
\frac{1}{C_{S C}^{2}}=\left(\frac{2}{\varepsilon \cdot A^{2} \cdot e \cdot N_{D}}\right) \cdot\left(V_{b i a s}-V_{f b}-\frac{k_{B} \cdot T}{e}\right)
$$

where $\varepsilon$ is the dielectric constant of the electrode, $\varepsilon_{0}$ is the vacuum permittivity, $A$ is the area of the electrode, $e$ is the charge of the electron, $N_{D}$ is the donor density, $V_{b i a s}$ is the applied potential, $k_{B}$ is the Boltzmann's constant and T is the temperature. The term $\frac{k_{B} \cdot T}{e}$ can be neglected due to its low value when compared to $V_{\text {bias }}$ and $V_{f b}$.

The value of the flat band potential is highly significant in the electrochemical characterization of a semiconductor-electrolyte interface, as it is related to the bottom energy of the conduction band. Together with the bandgap energy, it is used to describe the energy levels position at the electrode-electrolyte interface, determining the adequacy of a material to carry out or not any reaction, in this case, water splitting. Figure $7 \mathrm{a}, \mathrm{b}$ shows the Mott-Schottky plot at three representative frequencies for the bare $\mathrm{TiO}_{2}$ and $\mathrm{TiO}_{2}-\mathrm{BCN}$ samples. The value obtained for the flat band potential is $0.2 \pm 0.1 \mathrm{~V} v \mathrm{vs}$. RHE for bare $\mathrm{TiO}_{2}$, and $0.2 \pm 0.1 \mathrm{~V}$ vs. RHE for $\mathrm{TiO}_{2}-\mathrm{BCN}$. These results are in good agreement with values of the flat band potential previously obtained for $\mathrm{TiO}_{2}$ samples $[9,10]$, and with a previous report about the good electrocatalytic activity of BCN for OER, in which it was shown that the $\mathrm{BCN}$ layer does not affect the flat band potential of the underlying material [15]. Table S2 summarizes the main differences between $\mathrm{TiO}_{2}$ and $\mathrm{TiO}_{2}-\mathrm{BCN}$.

The slope of the Mott-Schottky fitting gives information about the dielectric constant of the material and its donor density. By using the data of the dielectric constant of $\mathrm{TiO}_{2}$ at $20^{\circ} \mathrm{C}$ reported by Wypych et al. [37] and the slope of bare $\mathrm{TiO}_{2}$, its donor density was determined to be independent of the frequency and has a value of $(1.53 \pm 0.02) 10^{19} \mathrm{~cm}^{-3}$ (Figure S9). This is in good agreement with the fact that the donor density is a characteristic parameter of the material and should not change with the frequency. However, as observed in [37], the dielectric constant is a function of the frequency. 
(a)

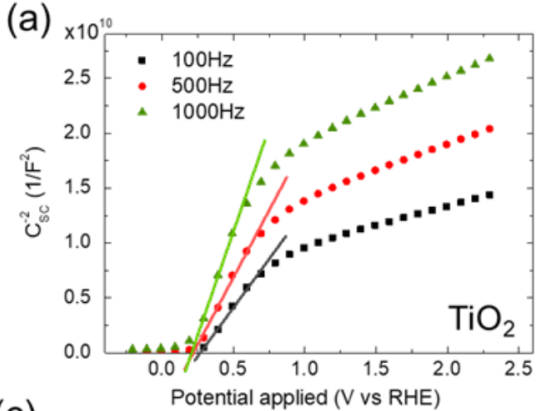

(c)

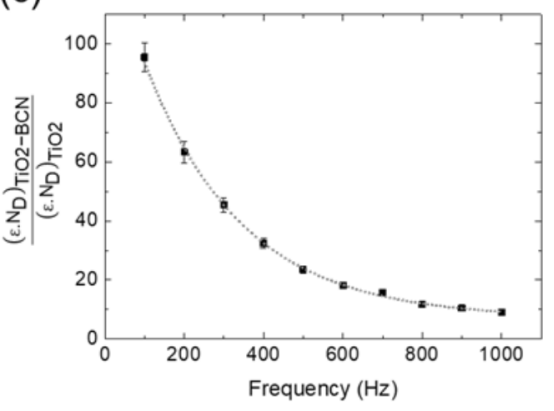

(b)

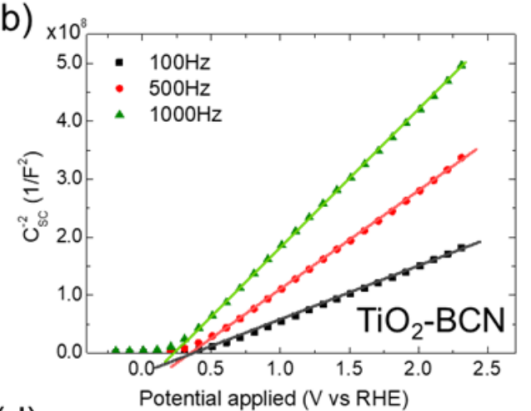

(d)

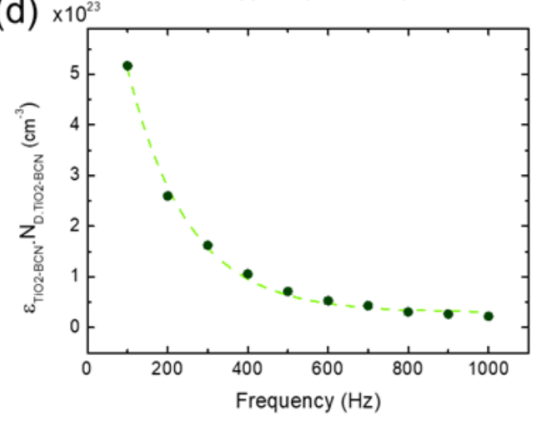

Figure 7. Mott-Schottky plot at three different frequencies for (a) sample $\mathrm{TiO}_{2}$ and (b) sample $\mathrm{TiO}_{2}-\mathrm{BCN}$. (c) Relationship between the dielectric constant and the density of donors $\left(\varepsilon \cdot N_{D}\right.$ factor) of the sample $\mathrm{TiO}_{2}-\mathrm{BCN}$ over that of the bare $\mathrm{TiO}_{2}$, as a function of the frequency. (d) $\varepsilon \cdot N_{D}$ factor for $\mathrm{TiO}_{2}-\mathrm{BCN}$ sample vs. the frequency. Fitting parameters of the exponential decay fittings represented by a grey dotted line in (c) and green dashed line in (d) are shown in Table S3.

By comparing the slopes of $\mathrm{TiO}_{2}\left(m_{\mathrm{TiO}_{2}}\right)$ and $\mathrm{TiO}_{2}-\mathrm{BCN}\left(m_{\mathrm{TiO}_{2}-\mathrm{BCN}}\right)$ at each frequency (Equation (5)) the relationship between the product of $\varepsilon$ and $N_{D}$ for both samples can be determined (Figure 7c).

$$
\frac{m_{\mathrm{TiO}_{2}}}{m_{\mathrm{TiO}_{2}-\mathrm{BCN}}}=\frac{\varepsilon_{\mathrm{TiO}_{2}-\mathrm{BCN}} \cdot N_{\mathrm{DTiO}_{2}-\mathrm{BCN}}}{\varepsilon_{\mathrm{TiO}_{2}} \cdot N_{\mathrm{DTiO}}}
$$

It can be concluded that the $\mathrm{TiO}_{2}-\mathrm{BCN}$ heterostructure has a greater value of factor $\varepsilon \cdot N_{D}$ than the bare $\mathrm{TiO}_{2}$. This can be partially ascribed to a higher $N_{D}$ in the $\mathrm{TiO}_{2}-$ $\mathrm{BCN}$ sample, induced by the plasma treatment during $\mathrm{BCN}$ growth. The higher donor density in the $\mathrm{TiO}_{2}-\mathrm{BCN}$ heterostructure is also in good agreement with the increase in the photocurrents in this sample in comparison with $\mathrm{TiO}_{2}$ (Figure 6b). Moreover, the dielectric constant of the $\mathrm{TiO}_{2}-\mathrm{BCN}$ heterostructure was also modified as the factor $\frac{\varepsilon_{\mathrm{TiO}_{2}}-\mathrm{BCN} \cdot N_{D \mathrm{TiO}_{2}}-\mathrm{BCN}}{\varepsilon_{\mathrm{TiO}} \cdot N_{D \mathrm{TiO}_{2}}}$ is not constant with the frequency. With the value of $\varepsilon_{\mathrm{TiO}_{2}} \cdot N_{D \mathrm{TiO}_{2}}$, the product $\varepsilon_{\mathrm{TiO}_{2}}-\mathrm{BCN}$. $N_{\mathrm{DTiO}_{2}}-\mathrm{BCN}$ vs. the frequency can be obtained, as shown in Figure $7 \mathrm{~d}$. This factor also follows an exponential decay tendency, similar to that obtained for $\mathrm{TiO}_{2}$ [37] in the region of $100-1000 \mathrm{~Hz}$, ascribed to the $\varepsilon_{\mathrm{TiO}_{2}}-\mathrm{BCN}$ as the $N_{D T \mathrm{TiO}_{2}-\mathrm{BCN}}$ is expected to be independent of the frequency.

To summarize our results, the photo-electrochemical response characterizations suggest that the $\mathrm{BCN}$ layer acts as an efficient electrocatalyst, improving electron transfer between the electrolyte and the underlying $\mathrm{TiO}_{2}$ electrode. It has been reported before that these good electrocatalytic properties are related to the heterogeneity of these compounds, formed by highly doped C-rich and h-BN domains. Substitutional doping and grain boundaries defects act as electrocatalytic sites for OER [15]. The improvement of the electrocatalytic properties of the samples is also confirmed by EIS measurements, that show an increase in the product of the donor density and the dielectric constant induced by $\mathrm{BCN}$ growth. On the other hand, it must be noticed that the $\mathrm{BCN}$ layer is very thin and absorbs mainly in the UV region [16], so it is not expected that it contributes to the creation of electron-hole pairs due to the appearance of new energy levels 


\section{Conclusions}

We have successfully changed the composition and structure of $\mathrm{TiS}_{3}$ by thermal annealing at $300{ }^{\circ} \mathrm{C}$ to obtain $\mathrm{TiO}_{2}$ without changing the nanoribbon morphology of the samples. The XRD and Raman measurements reveal a change from $\mathrm{TiS}_{3}$ monoclinic to anatase tetragonal $\mathrm{TiO}_{2}$, and the diffuse reflectance measurements a change in the gap from $0.94 \pm 0.04 \mathrm{eV}$ to $3.3 \pm 0.4 \mathrm{eV}$. On top of the $\mathrm{TiO}_{2}$ nanoribbons, we have successfully grown a $\mathrm{BCN}$ layer by plasma-enhanced CVD without affecting the $\mathrm{TiO}_{2}$ structure and morphology as it has been proved by XRD, Raman and XPS techniques. The analysis of the chemical composition and bonding scheme of the $\mathrm{BCN}$ layer revealed that our layer is composed of $\mathrm{C}$ and h-BN nanodomains with high mutual doping levels of $\mathrm{B}$ and $\mathrm{N}$ in $\mathrm{C}$, and of $\mathrm{C}$ in $\mathrm{BN}$, respectively.

The heterostructure $\mathrm{TiO}_{2}-\mathrm{BCN}$ has been measured in a photoelectrochemical cell, corroborating the good photoelectrocatalytic properties of the BCN to carry out the OER when compared with the bare $\mathrm{TiO}_{2}$ substrate. Cycling stability tests and Raman measurements after the experiments demonstrated that the $\mathrm{BCN}$ layer remained on the sample and that the structure of the sample has not changed, showing the high stability of our samples. Finally, with EIS measurements, flat band potentials for $\mathrm{TiO}_{2}$ and $\mathrm{TiO}_{2}-\mathrm{BCN}$ have been determined to have the same value $(0.2 \pm 0.1 \mathrm{~V}$ vs RHE). By analyzing the slopes of the Mott-Schottky plots, it has been determined that the factor $\varepsilon \cdot N_{D}$ is higher in the case of the $\mathrm{TiO}_{2}-\mathrm{BCN}$ sample which is in good agreement with the increase observed in the photocurrents. In conclusion, the present results point out the excellent photoelectrocatalytic properties of the $\mathrm{BCN}$ as a metal-free material to be used in water splitting devices.

Supplementary Materials: The following are available online at https://www.mdpi.com/article/10 .3390/ma14195490/s1, Figure S1: Photograph of a sample before and after the oxidation, Figure S2: Scheme of the photoelectrochemical cell used in this work, Figure S3: Raman spectra of one of the samples with BCN. The spectra have been measured in an external nanoribbon (border) and one in the center of the sample, Figure S4: XPS measurement between $384 \mathrm{eV}$ and $413 \mathrm{eV}$. N1s is overlapped with a small signal of the Ta4 $\mathrm{p}_{3 / 2}$ peak, ascribed to the tantalum clips used to fix the sample to the sample holder, Figure S5: Photocurrent of $\mathrm{TiO}_{2}-\mathrm{BCN}$ heterostructure under Xe lamp illumination at $0.6 \mathrm{~V}$ vs Ag/ $\mathrm{AgCl}$ in $0.1 \mathrm{M} \mathrm{KOH}$ aqueous solution, Figure S6: (a) LSW at different scan rates (b) CV at different scan rates (c) Difference between the anodic and cathodic current of the CV measurements, Figure S7: To prove the stability of our electrode, series of cyclic voltammetry at $0.05 \mathrm{mV} / \mathrm{s}$ have been done. This figure shows the current at the maximum potential applied (1.8V vs RHE) for each one of the cycles, for the $\mathrm{TiO}_{2}-\mathrm{BCN}$ sample in $1.0 \mathrm{M} \mathrm{KOH}$ aqueous electrolyte, Figure S8: Raman spectra of $\mathrm{TiO}_{2}$ and $\mathrm{TiO}_{2}-\mathrm{BCN}$ before the photoelectrochemical measurements (PEC) and $\mathrm{TiO}_{2}-\mathrm{BCN}$ after the PEC, Figure S9: Donor density of the $\mathrm{TiO}_{2}$ sample, Table S1: Position (binding energy, BE), full peak width at a half maximum (FWHM), and relative intensities (with and without oxygen contribution) for the $\mathrm{TiO}_{2}-\mathrm{BCN}$ and bare $\mathrm{TiO}_{2}$ samples, Table S2: Comparison between $\mathrm{TiO}_{2}$ and $\mathrm{TiO}_{2}-\mathrm{BCN}$ of the current density in dark condition at $1.85 \mathrm{~V}$ vs $\mathrm{RHE}\left(\mathrm{I}_{\text {dark }}\right)$, photocurrent at $1.85 \mathrm{~V}$ vs $\mathrm{RHE}\left(\mathrm{I}_{\mathrm{ph}}\right)$ and flat band potential, Table S3: Fitting parameters of graphs Figure $7 \mathrm{c}, \mathrm{d}$, to an exponential decay: $y=y_{0}+A \cdot \exp \left(-\frac{f}{t}\right)$ where $y$ is the parameter of the Y-axis, and $f$ is the frequency.

Author Contributions: Conceptualization: N.J.-A., F.L., I.J.F., E.F. and J.R.A., morphological and structural characterization: N.J.-A., E.F., F.L., I.J.F. and J.R.A. optical characterization: N.J.-A., E.F., F.L., I.J.F. and J.R.A. photoelectrochemical measurements: N.J.-A., I.J.F. and F.L. surface chemical composition and element distribution: N.J.-A., A.G., M.S., C.M. and M.G.B. writing-original draft preparation: N.J.-A. writing-review and editing: I.J.F., F.L., A.G., C.M., M.S., E.F., J.R.A. and M.G.B. All authors have read and agreed to the published version of the manuscript.

Funding: This research was funded by Spanish MICINN under RTI2018-099794-B-I00 grant.

Institutional Review Board Statement: Not applicable.

Informed Consent Statement: Not applicable.

Data Availability Statement: Not applicable. 
Acknowledgments: Authors wish to thank technical assistance from F. Moreno, SIdI and Segainvex Facilities at Universidad Autónoma de Madrid. Jiménez-Arévalo, N. acknowledges Comunidad de Madrid and European Social Fund for the PEJD-2019-PRE/IND-16301 predoctoral contract, and Universidad Autónoma de Madrid and Banco Santander for the mobility grant Ayudas UAMSantander para la movilidad de jóvenes investigadores to carry out the XPS measurements. Giampietri, A. and Mariani, C. thank the support by PRIN FERMAT (No, 2017KFY7XF) from Italian Ministry MIUR and by Sapienza Ateneo Funds.

Conflicts of Interest: The authors declare no conflict of interest.

\section{References}

1. Lewis, N.S.; Nocera, D.G. Powering the planet: Chemical challenges in solar energy utilization. Proc. Natl. Acad. Sci. USA 2006, 103, 15729-15735. [CrossRef]

2. Osterloh, F.E.; Parkinson, B.A. Recent developments in solar water-splitting photocatalysis. MRS Bull. 2011, 36, 17-22. [CrossRef]

3. Van der Krol, R.; Grätzel, M. Photoelectrochemical Hydrogen Production; Springer: New York, NY, USA, 2012.

4. Lewis, N.S. Toward cost-effective solar energy use. Science 2007, 315, 798-801. [CrossRef]

5. Fujishima, A.; Honda, K. Electrochemical Photolysis of Water at a Semiconductor Electrode. Nature 1972, 238, 37-38. [CrossRef] [PubMed]

6. Walter, M.G.; Warren, E.L.; McKone, J.R.; Boettcher, S.W.; Mi, Q.; Santori, E.A.; Lewis, N.S. Solar water splitting cells. Chem. Rev. 2010, 110, 6446-6473. [CrossRef] [PubMed]

7. Chen, X.; Shen, S.; Guo, L.; Mao, S.S. Semiconductor-based photocatalytic hydrogen generation. Chem. Rev. 2010, 110, 6503-6570. [CrossRef] [PubMed]

8. Jamesh, M.I.; Xiaoming, S. Recent progess on earth abundant electrocatalysts for oxygen evolution reaction (OER) in alkaline medium to achieve efficient water splitting- A review. J. Power Sources 2018, 400, 31-68. [CrossRef]

9. Berger, T.; Monllor-Satoca, D.; Jankulovska, M.; Lana-Villareal, T.; Gómez, R. The electrochemistry of nanostructured titanium dioxide electrodes. ChemPhysChem 2012, 13, 2824-2875. [CrossRef]

10. Cao, F.; Xiong, J.; Wu, F.; Liu, Q.; Shi, Z.; Yu, Y.; Wang, X.; Li, L. Enhanced photoelectrochemical performance from rationally designed anatase/rutile $\mathrm{TiO}_{2}$ heterostructures. ACS Appl. Mater. Interfaces 2016, 8, 12239-12245. [CrossRef]

11. Hu, S.; Shaner, M.R.; Beardslee, J.A.; Lichterman, M.; Brunschwig, B.S.; Lewis, N.S. Amorphous TiO 2 coatings stabilize Si, GaAs, and GaP photoanodes for efficient water oxidation. Science 2014, 344, 1005-1009. [CrossRef]

12. Li, Z.; Chen, Y.; Ma, T.; Jiang, Y.; Chen, J.; Pan, H.; Sun, W. 2D Metal-Free Nanomaterials Beyond Graphene and its Analogues toward Electrocatalysis Applications. Adv. Energy Mater. 2021, 11, 2101202. [CrossRef]

13. Chhetri, M.; Maitra, S.; Chakraborty, H.; Waghmare, U.V.; Rao, C.N.R. Superior performance of borocarbonitrides, BxCyNz, as stable, low-cost metal-free electrocatalysts for the hydrogen evolution reaction. Energy Environ. Sci. 2016, 9, 95-101. [CrossRef]

14. Rao, C.N.R.; Chhetri, M. Borocarbonitrides as Metal-Free Catalysts for the Hydrogen Evolution Reaction. Adv. Mater. 2019, 31, 1-13. [CrossRef]

15. Jiménez-Arévalo, N.; Leardini, F.; Ferrer, I.J.; Ares, J.R.; Sánchez, C.; Abdelnabi, M.M.S.; Betti, M.G.; Mariani, C. Ultrathin Transparent B-C-N Layers Grown on Titanium Substrates with Excellent Electrocatalytic Activity for the Oxygen Evolution Reaction. ACS Appl. Energy Mater. 2020, 3, 1922-1932. [CrossRef]

16. Leardini, F.; Jiménez-Arévalo, N.; Ferrer, I.J.; Ares, J.R.; Molina, P.; Gómez Navarro, C.; Manzanares, Y.; Granados, D.; Urbanos, F.J.; García-García, F.J.; et al. A fast synthesis route of boron-carbon-nitrogen ultrathin layers towards highly mixed ternary B-C-N phases. 2D Mater. 2019, 6, 035015. [CrossRef]

17. Ghasemi, F.; Frisenda, R.; Flores, E.; Papadopoulos, N.; Biele, R.; Perez de Lara, D.; Van der Zant, H.S.J.; Watanabe, K.; Taniguchi, T.; D'Agosta, R.; et al. Tunable Photodetectors via In Situ Thermal Conversion of $\mathrm{TiS}_{3}$ to $\mathrm{TiO}_{2}$. Nanomaterials 2020, 10, 711. [CrossRef] [PubMed]

18. Ferrer, I.J.; Maciá, M.D.; Carcelén, V.; Ares, J.R.; Sánchez, C. On the photoelectrochemical properties of TiS 3 films. Energy Procedia 2012, 22, 48-52. [CrossRef]

19. Ferrer, I.J.; Ares, J.R.; Clamagirand, J.M.; Barawi, M.; Sánchez, C. Optical properties of titanium trisulphide (TiS 3 ) thin films. Thin Solid Films 2013, 535, 398-401. [CrossRef]

20. Massimi, L.; Betti, M.G.; Caramazza, S.; Postorino, P.; Mariani, C.; Latini, A.; Leardini, F. In-Vacuum thermolysis of ethane 1,2-diamineborane for the synthesis of ternary borocarbonitrides. Nanotechnology 2016, 27, 435601. [CrossRef]

21. Leardini, F.; Flores, E.; Ferrer, I.J.; Ares, J.R.; Sánchez, C.; Molina, P.; van der Meulen, H.P.; Navarro, C.G.; Polin, G.L.; Urbanos, F.J.; et al. Chemical vapor deposition growth of boron-carbon-nitrogen layers from methylamine borane thermolysis products. Nanotechnology 2018, 29, 025603. [CrossRef]

22. Pawbaje, A.S.; Island, J.O.; Flores, E.; Ares, J.R.; Sánchez, C.; Ferrer, I.J.; Jadkar, S.R.; van der Zant, H.S.J.; Castellanos-Gomez, A.; Late, D.J. Temperature-Dependent Raman Spectroscopy of Titanium Trisulfide ( $\left.\mathrm{TiS}_{3}\right)$ Nanoribbons and Nanosheets. ACS Appl. Mater. Interfaces 2015, 43, 24185-24190. [CrossRef] [PubMed]

23. Ohsaka, T. Temperature Dependence of the Raman Spectrum in Anatase $\mathrm{TiO}_{2}$. J. Phys. Soc. Jpn. 1980, 48, 1661-1668. [CrossRef] 
24. Zhang, Y.; Wu, W.; Zhang, K.; Liu, C.; Yu, A.; Peng, M.; Zhai, J. Raman Study of 2D anatase TiO 2 nanosheets. Phys. Chem. Chem. Phys. 2016, 18, 32178-32184. [CrossRef] [PubMed]

25. Melendres, C.A.; Narayanasamy, A.; Maroni, V.A.; Siegel, R.W. Raman Spectroscopy of nanophase TiO $2 . J$. Mater. Res. 1989, 4, 1246-1250. [CrossRef]

26. Mammone, J.F.; Sharma, S.K.; Nicol, M. Raman study of rutile $\left(\mathrm{TiO}_{2}\right)$ at high pressures. Solid State Commun. 1980, $34,799-802$. [CrossRef]

27. Murphy, A.B. Modified Kubelka-Munk model for calculations of the reflectance of coatings with optically-rough surfaces. J. Phys. D Appl. Phys. 2006, 39, 3571. [CrossRef]

28. Xu, B.; Sohn, H.Y.; Mohassab, Y.; Lan, Y. Structures, preparation and applications of titanium suboxides. RSC Adv. 2016, 6, 79706-79722. [CrossRef]

29. Diebold, U.; Mandey, T.E. TiO ${ }_{2}$ by XPS. Surf. Sci. Spectra 1996, 4, 227-231. [CrossRef]

30. Göpel, W.; Anderson, J.A.; Frankel, D.; Jaehnig, M.; Philips, K.; Schäfer, J.A.; Rocker, G. Surface defects of TiO 2 (110): A combined XPS, XAES and ELS study. Surf. Sci. 1984, 139, 333-346. [CrossRef]

31. Guillemot, F.; Porté, M.C.; Labrugère, C.; Baquey, C. Ti4+ to Ti3+ conversion of $\mathrm{TiO}_{2}$ uppermost layer by low-temperature vacuum annealing: Interest for titanium biomedical applications. J. Colloid Interface Sci. 2002, 255, 75-78. [CrossRef]

32. Nappini, S.; Bondino, F.; Píš, I.; Chelleri, R.; Greco, S.L.; Lazzarino, M.; Magnano, E. Chemical composition and interaction strength of two-dimensional boron-nitrogen-carbon heterostructures driven by polycrystalline metallic surfaces. Appl. Surf. Sci. 2019, 479, 903-913. [CrossRef]

33. Attri, R.; Sreedhara, M.B.; Rao, C.N. R Compositional tuning of electrical and optical properties of PLD-generated thin films of 2D borocarbonitrides (BN)1-x (C) x. ACS Appl. Electron. Mater. 2019, 1, 569-576. [CrossRef]

34. Ci, L.; Song, L.; Jin, C.; Jariwala, D.; Wu, D.; Li, Y.; Srivastava, A.; Wang, Z.F.; Storr, K.; Balicas, L.; et al. Atomic layers of hybridized boron nitride and graphene domains. Nat. Mater. 2010, 9, 430-435. [CrossRef] [PubMed]

35. Ong, C.W.; Huang, H.; Zheng, B.; Kwok, R.W.M.; Hui, Y.Y.; Lau, W.M. X-ray photoemission spectroscopy of nonmetallic materials: Electronic structures of boron and BxOy. J. Appl. Phys. 2004, 95, 3527. [CrossRef]

36. Schneider, J.; Matsuoka, M.; Takeuchi, M.; Zhang, J.; Horiuchi, Y.; Anpo, M.; Bahnemann, D.W. Understanding TiO 2 Photocatalysis: Mechanisms and materials. Chem. Rev. 2014, 114, 9919-9986. [CrossRef] [PubMed]

37. Wypych, A.; Bobowska, I.; Tracz, M.; Opasinska, A.; Kadlubowski, S.; Krzywania-Kaliszewska, A.; Grobelny, J.; Wojciechowski, P. Dielectric Properties and Characterisation of Titanium Dioxide Obtained by Different Chemistry Methods. J. Nanomater. 2014, 2014, 1-9. [CrossRef] 